\title{
EVALUATION OF POLLENS AS AEROALLERGEN IN SHKODRA DISTRICT, ALBANIA
}

\author{
Mirela Lika (Çekani) $)^{1^{*}}$ \\ ${ }^{1 *}$ University of Tirana,Department of Biology, Tirana, Albania; \\ *Corresponding Author Mirela Lika (Çekani), e-mail: mirela.lika@fshn.edu.al;
}

Received May 2021; Accepted June 2021; Published August 2021;

DOI: https://doi.org/10.31407/ijees11.404

\begin{abstract}
In this study, aerogenic allergies caused by aeroallergens, mainly pollen, were evaluated. Information about aeroallergens, their structure, or composition and impact on allergies was initially analyzed. Also, based on the literature and studies that have been conducted, the mechanisms of development of allergic reactions and their effects on the human body have been evaluated. Since pollens are one of the main causes of allergies and promote the manifestation of various reactions and symptoms. Specifically, this work consisted of the morphological study of pollens of allergic plants in the area of Shkodra and several people affected by pollen allergies were studied. Statistical data processing was also performed by 100 allergic patients, studying the families of the most common allergic plants in the area, and the association of these pollens with allergies in humans, as well as distributions with the most affected age group and sex, as well as the most common diagnosis that these patients present. The working methodology consisted in the collection and determination of trees and pollen, the cause of various allergies, according to clearly defined methodologies. The results have been expected, for the association of pollens with the occurrence of allergies, mainly of the respiratory tract in humans.
\end{abstract}

Keywords: aeroallergen, allergy, pollen, bacteria, fungi, mechanism of allergy, early-stage reactions, late-stage reactions, chemical mediator, allergen 